Case Report

Oopen Access

CrossMark

\title{
Hamartoma of the base of the tongue
}

\begin{abstract}
Hamartomas of the tongue are rare. A case of a 17- years old male with hamartoma at the base of the tongue is reported. The diagnosis was confirmed by a histopathological and immunohistochemical examination of the mass after excisional biopsy under general anesthesia. The literature is reviewed and discussed.
\end{abstract}

Keywords: hamartoma, base of the tongue
Volume 2 Issue 5 - 2015

\section{Sohair Mohammed Elameen}

Department of Otolaryngology, ENT Hospital-Khartoum, Sudan

Correspondence: Sohair Mohammed Elameen, Department of Otolaryngology, ENT Hospital-Khartoum, Sudan, Tel 00971501507910,Email sohairent@gmai.com

Received: March 23, 2015 | Published: June 09, 2015

\section{Introduction}

The term "hamartoma" was first used by Albrecht in 1904. Hamartomas are defined as tumor-like, but primary non-neoplastic malformations or inborn errors of tissue development, characterized by an abnormal mixture of tissues indigenous to a part of the body with an excess of one or more of the cellular components. ${ }^{2}$ It may occur in any organ of the body and are common in the spleen, liver, kidneys, lungs and pancreas. However, hamartomas of the tongue are extremely rare. ${ }^{2}$

\section{Case report}

A 17-years old male presented to the ENT referred clinic on November 2013 with history of progressive dysphagia for solid and change of voice for the last 3years. His symptoms started with dysphagia for solid, gradual in onset progressive in nature, associated with nasal regurge but no odynophagia, weight loss, fever, anorexia or other constitutional symptom, also there was no shortness of breathing but there was change of voice, hot potato in nature. There were no other symptoms associated with cardiopulmonary, genitourinary, musculoskeletal, nervous systems. There was no significant past, family, drug or social history.

\section{On examination}

Patient fully conscious, vital signs were normal stable:

a. Heart rate: 76 beat/minute

b. Respiratory rate: $12 /$ minute

c. Blood pressure: $110 / 70$

The indirect laryngoscope revealed a mass extending from the left side of the base of the tongue but the inferior limit is invisible because of its size. It was covered with normal mucosa, the mass completely obscuring the laryngeal inlet view.

No cervical lymph nodes were palpable in the neck. Rest of examination of the ear, nose, and neck, as well as general physical examination, was unremarkable.

\section{Investigation}

Hematological examinations were normal
a. Complete blood count
b. Renal function test and electrolytes
c. Bleeding profile

Radiological examination of the neck

1. A thyroid uptake scan was negative for activity in the mass.

2. X ray lateral view showed oropharyngeal soft tissue shadow over the epiglottis

3. CT scan of the neck showed suspicious large lobulated heterogeneous enhancing soft tissue mass

Then the decision of examination under general anesthesia and biopsy was taken (Figure $1 \& 2$ ).

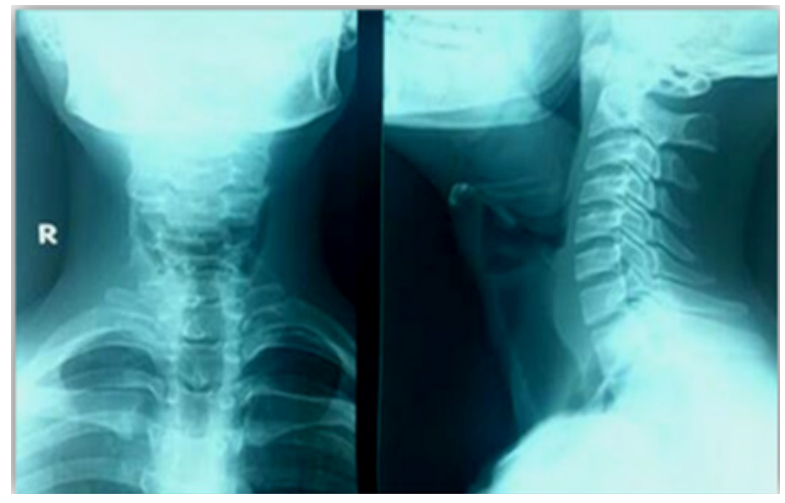

Figure I Lateral soft tissue neck X-ray showing a sizable opacity (white star) projecting from the oropharynx into the hypopharynx causing significant encroachment upon the airways.

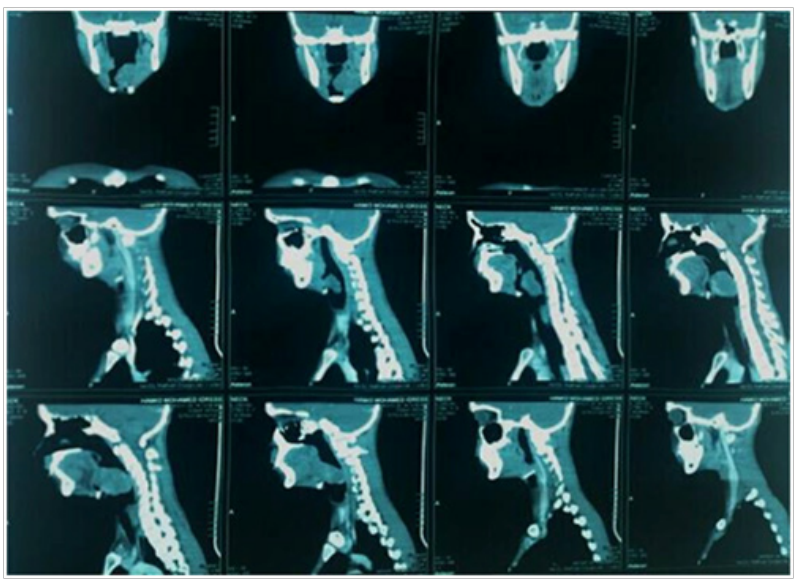

Figure 2 Coronal and sagittal reconstructed MDCT images showing the origin of the mass from the left fauces (white arrow) and its extension into the hypopharynx causing significant narrowing of the airways (red arrow). 


\section{Operative findings}

Intubation was difficult, so tracheotomy was done for anesthetic purposes. There was a firm pedunculated mass arising from the left side of the base of tongue extending to the hypopharynx. No other masses or ulcerations were seen in the area. The oral mass was found to be capsulated, dissected from the tongue base and excised completely and its base was ligated .macroscopically the mass was multilobular, firm, measuring about $8 \times 5 \times 6 \mathrm{~cm}$. Histopathological examination revealed hamartomatus malformation confirmed by immunohistochemistry.

Patient took orally in the 2nd day of the operation and tracheotomy was closed 2days later. Endoscopic follow up in 6 and 12months revealed no recurrence.

\section{Discussion}

This patient is the first case of hamartoma base of the tongue reported in Sudan. Hamartomas composed of vascular tissue, or hemangiomas, are most common in the head and neck, mature cartilage outgrowths have been described in the nasal cavity, larynx, trachea, bronchi, and lungs. ${ }^{3}$

Lingual hamartoma may occur in isolation or in association with syndromes such as oral-facial digital syndrome 4 its presentation as isolated anomaly is extremely rare, with only 15 previously reported patients, 13 of whom were children. ${ }^{5}$ This Table 1 shows some patients with lingual hamartoma in the English-written medical journals. ${ }^{6}$

Hamartomas do not clearly represent either neoplastic or inflammatory disorders. ${ }^{7}$ The differential diagnosis of mass in the tongue base include lingual thyroid, thyroglossal cyst, dermoid cyst which ruled out preoperatively in this patient by using the thyroid and CT scan respectively, other differential diagnoses include sarcoma ,rhabdomyoma, granular cell tumor, schwannoma, and neurofibroma, but these would be relatively easy to differentiate microscopically and by immunohistochemical markers.

As a rule, the treatment for hamartoma is complete removal; recurrence caused by incomplete excision has been reported. ${ }^{8}$

\section{Conclusion}

Although hamartoma of the base of the tongue is rare it should be considered in the differential diagnosis of the tongue base masses and complete removal is mandatory to prevent the recurrence.

\section{Acknowledgements}

I am extremely thankful and indebted to Dr. Omer Elsayed, Dr. Mahmoud Aboganaya for sharing their expertise and our young proactive Dr. Azza for her help with the patient. I want to take this opportunity to express gratitude to Dr. Layla from radiology department and Mr. Saravana in Thumbay hospital for their help and support.

\section{Conflicts of interest}

There is no potential conflict of interests related to the exclusive nature of this paper.

\section{Funding}

None.

\section{References}

1. Edgerton MT. The treatment of hemangiomas with special reference to the role of steroid therapy. Ann surg. 1976;183(5):517-532.

2. Albrecht E. Uber Hamartome Verh. Dtsch Geo Pathol . 1904;7:153-157.

3. Endo R, Matsuda H, Takahashi M, et al. Respiratory epithelial adenomatoid hamartoma in the nasal cavity. Acta Otolaryngol. 2002;122(4):398-400.

4. Gorlin RJ, Psaume J. Orodigitofacial dystosis: a new syndrome- a study of 22 cases. J Pediatr. 1962;61:520-30.

5. Owen G, Berry J, Bicknell P. Hamrtoma of the tongue. J Laryngol Otol. 1993;107(4):363-367.

6. Takimoto T, Yoshizaki T, Umeda R. Hamrtoma of the tongue. International Journal of Pediatric Otorhinolaryngologv. 1989;18(2):157-161.

7. Nussbaum M, Tan S, Som ML. Hemangiomas of the salivary glands. Laryngoscope . 1976;86(7):1015-1019.

8. Batsakis JG. Pathology consultation. Nomenclature of developmental tumors. Ann Otol Rhinol Laryngol. 1984;93(1 pt 1):98-99. 